\title{
Canadian Global Leadership Students Engaged in Strategic Partnerships in Ecuador
}

\author{
By \\ Wendy Rowe, Wanda Krause, Gary Hayes, Lisa Corak, Robert Sean Wilcox, Robert Vargas, \\ Fabricio Varela, Fabricio Cordova, Shina Boparai and Gesow Azam
}

\begin{abstract}
Recognizing the need to build global minded citizens, higher education institutions are increasingly trying to find ways to leverage their international programs to develop students' intercultural competence. The MA in Global Leadership at Royal Roads University, Canada, created an international partnership in Ecuador that serves to go beyond the traditional student study abroad or service learning focus, and instead focuses on developing competencies of global mindedness and strategic relationships. In this paper, we present an analysis on how an international student group engaged in building dynamic partnerships within a Global South country to create change for sustainable development initiatives of mutual concern. Through a case example, we describe how these partnerships evolved and adapted in ways that enhanced the learning needs of the students while simultaneously supporting the development of new educational opportunities for Ecuadorians. To illustrate, this paper delineates the activities that members of the program undertook to connect and develop a mutuality of relationship across diverse stakeholders in Ecuador. The authors analyze this network building process from the perspective of cultural context, building trust and influence, and responding to social development needs in host communities.
\end{abstract}

Key words: leadership development, study abroad, Ecuador, international partnerships, international higher education 


\section{Canadian Global Leadership Students Building Strategic Relationships in Ecuador}

In 2016, Ecuadorian military officers, Lt Col Robert Vargas and Lt Col Fabricio Varela and, invited ten students, a staff person and a professor from a Canadian University global leadership program to visit Ecuador. Members of the leadership program responded to the invitation, eager to learn about the country, strengthen competencies in global awareness and intercultural knowledge, and share their theoretical knowledge and experiences in global leadership with the Ecuadorian military leaders. This paper tells the story and significance of this first engagement of Canadian students in Ecuador (and subsequent trips), and also describes the activities that occurred in between trips to build ongoing and sustainable relationships between the Canadian University program and key Ecuadorians across sectors of the military as well as in various indigenous Ecuador communities. The paper elaborates on the relationships forged with other sectors of higher education, and in areas of indigenous community development, ecotourism, environmental activism, and social entrepreneurship. This story focuses on how the Canadians and the Ecuadorians leveraged ongoing personal relationships strategically in pursuit of mutual and individual goals and objectives. The strategic partnerships are based on principles and competencies of global leadership that form and underlie the MA in Global Leadership (MAGL) program at Royal Roads University, Victoria, Canada. The story and lessons presented in this paper reflect the perspectives and experiences of the authors who as staff, faculty and students of MAGL, participated in the trips to Ecuador. Additional elements of this narrative come from other students who wrote about their experiences in Ecuador and what those experiences meant to them. The objective of the trips to Ecuador were not designed as traditional student study abroad or service learning events, but rather to be a journey of travel through different parts of the country so that students could witness knowledge-sharing opportunities and build partnerships with members of communities within the military, indigenous organizations, university institutions, and social enterprises..

Although the paper provides anecdotal reports, it does not focus on a systematic evaluation of student learning outcomes. Rather, it delineates how the strategic relationships were built and experienced by various members of the Canadian global leadership program students, staff and faculty, and the Ecuadorians. It seeks to unpack how these relationships contributed to partnership projects in different sectors of the country, namely partnership projects that created a context for each annual incoming group of students to experience and witness global leadership in action. Table 1 provides a list of the partnership projects with which students, staff and faculty engaged during their time in the country. Some of these strategic partnership projects led to student capstone projects, which will be described in a later section of this paper.

Table 1. Strategic Partnerships Project in Ecuador

\begin{tabular}{|l|l|l|}
\hline $\begin{array}{l}\text { Host Organization or } \\
\text { Group }\end{array}$ & Individual Partners in Ecuador & Theme of Partnership \\
\hline Ecuador Military & $\begin{array}{l}\text { Lt Col. Fabricio Varela } \\
\text { Lt Col. Robert Vargas } \\
\text { Major Fabricio Cordova } \\
\text { Major Freddy Escudero } \\
\text { *IWIAS School (Hosted by the } \\
\text { Comandante de la Escuela de IWIAS, } \\
\text { introduced by Second Lieutenant Bryan } \\
\end{array}$ & $\begin{array}{l}\text { Leadership Education for } \\
\text { C. and Lt Col Fabricio Varela. }\end{array}$ \\
& & \\
& & \\
\hline
\end{tabular}




\begin{tabular}{|l|l|l|}
\hline \multirow{5}{|l}{} & $\begin{array}{l}\text { Eloy Alfaro Military Cadet School, } \\
\text { hosted by Director de la Escuela } \\
\text { Superior Militar 'Eloy Alfaro' as } \\
\text { introduced by Lt Col Fabricio Varela } \\
\text { War College (hosted by Director } \\
\text { Academia de Guerra del Ejército }, \\
\text { introduced by Lt Col Robert Vargas and } \\
\text { Lt Col. Fabricio Varele }\end{array}$ & \\
\hline ESPE University & $\begin{array}{l}\text { Sara Durán, } \\
\text { International Cooperation Director } \\
\text { (introduced by Robert Vargas) } \\
\text { Maria de los Ángeles Batson } \\
\text { International Agreements Advisor } \\
\text { Dr. Klever Bravo }\end{array}$ & $\begin{array}{l}\text { Higher Education } \\
\text { Pathways for Ecuadorians }\end{array}$ \\
\hline $\begin{array}{l}\text { Simiatug Women's } \\
\text { Cooperative }\end{array}$ & $\begin{array}{l}\text { Grupo Simiatug Llakta (introduced } \\
\text { through RRU affiliates Fernando and } \\
\text { Maria (Sli Ecuador) ... Ecuador) }\end{array}$ & $\begin{array}{l}\text { Economic Development in } \\
\text { Indigenous Community }\end{array}$ \\
\hline $\begin{array}{l}\text { Salinas Community } \\
\text { Development }\end{array}$ & $\begin{array}{l}\text { Salinerto office of tourism } \\
\text { (in the village of Salinas) }\end{array}$ & $\begin{array}{l}\text { Community Development } \\
\text { and Networking }\end{array}$ \\
\hline $\begin{array}{l}\text { Salcedo - Nagsiche River } \\
\text { Basin Community }\end{array}$ & $\begin{array}{l}\text { Moisés Padilla (introduced by Hugo - a } \\
\text { friend of Major Fabricio Cordova) }\end{array}$ & \begin{tabular}{l} 
Community Development \\
\hline
\end{tabular} \\
\hline
\end{tabular}

\section{The Country of Ecuador}

Ecuador is a developing economy country in South America of tremendous geo-political, social and economic contrasts, divisions and needs (Velz, MacLeod and Knapp, 2018; World Bank Group, 2017)). The eco-diversity of the Galapagos Islands has long attracted international attention but, for many years, the continental regions received limited focus, except when it came to exploiting oil or mineral reserves and trading in agricultural exports (e.g. bananas, cocoa and roses). However, in the recent decade, business and public-private partnerships interests have expanded to diversify agricultural production, promote agro-forestry, support infrastructure projects, strengthen domestic tourism, and address water security and poverty issues (Rubalcaba et al., 2017). With these business ventures, and the recent shift in political power structures in the country, there is heightened awareness that the country needs to enhance relationships beyond business trade to include international NGOs and educational institutions, and to build global partnerships that support the social and economic development of local communities. Key actors in Ecuador are seeking new global relationships and changes in line with its geo-political and cultural identity (Collyns, 2018). This emphasis on a globally conscious Ecuador is articulated in the mission of the Pachaysana Institute in Quito, Ecuador ( Pachaysana Institute, 2018).

[to]empower[ing]local communities while simultaneously educating global leaders. We are part of the Fair Trade Learning movement and practice decolonial education. Local counterparts and international students learn together, studying development, sustainability, identity and globalization, all in the context of the reality of our local community" (para. 1). 
Canadian Students Engaged in Ecuador Partnerships

\section{International Development and a Role for Universities}

Dominant approaches to international development have been top down efforts to transform the economic and social foundations of a country through large-scale agriculture, environment, health, education, infrastructure and technology initiatives (Burns and Worsley, 2015). In most cases, external agents have controlled international development efforts with limited local participation or local ownership (Kingsbury et al. 2016: 225). Relationships between the external donors of aid, or technical assistance, and members of the local communities have often been paternalistic, contributing to inequality and the dependency and destruction of local cultures (Appel, 1990). Bouwen, Crapps and Santos (2009) argue that the external agency technology aid approaches to social and economic development have been particularly ineffective. They strongly advocate for more relational and equitable approaches involving external parties from the developed countries with locals of the developing country. NGOs and other civil society organizations have stepped in to embrace these approaches, recognizing that building global partnerships and collaborations is critical to working with local citizens in economically and socially disadvantaged communities (ibid).

In particular, universities and colleges in North America and Europe, which promote international student learning, have embraced the partnership building and relational perspective to international development (Paige, Fry, Stallman, Josic, and Jon, 2009: 31). Recognizing the need to build capacity in students to be globally minded and contributing citizens, these institutions are trying to find ways to leverage their international programs to develop students' intercultural competence (ibid; Green et al., 2008; IIE, 2013; Lincoln Commission, 2005; Heffernan and Poole, 2005). Consequently, many of the international study initiatives involve formal partnerships between the academic institutions and Global South NGOs, or educational partners to build new capacities and address critical international issues, such as health crises, water and food shortages, environmental threats to the jungle, and wildlife conservation (https://www.pachaysana.org/rehearsing-change).

Reports on international study initiatives have tended to focus on participant outcomes such as satisfaction and student learning in personal awareness, cultural values, and communication skills (Yank, Lu, Webster, Chau, and Ma, 2016; Pless, Maak, and Stahl, 2011) with less attention to the development of the program's relationship with the international partners, and the impact on the host country. Little is known about how the University works with the host country to develop the learning context and strategic partnerships of value to both parties, how students engage with the host country, and whether the partnership relationship between the University program and the host country becomes sustainable and ongoing for future groups of students. This paper seeks to illustrate the significance of students involved in building informal international partnerships and thus goes beyond the typical analysis of study abroad literature which primarily focuses on the value to students who have left their home country to learn in other country contexts (Stebleton, Soria, and Cherney 2013; Pedersen, 2015).

In this paper, we briefly discuss literature on the benefits of student abroad trips for the development of global leadership competencies. We then proceed beyond this context to the role of students in building strategic relationships in their international host country. Students develop enhanced global leadership competencies when they contribute to the development of strategic international partnerships. We address a form of international relationship building that is evolving and adaptive in ways that enhance the learning needs of the students; and simultaneously contributing to the development of new educational and international development opportunities for their international partners. To illustrate our case and provide insight into the learning outcomes of global leadership and strategic partnership building, we describe the activities that members of the MAGL program (students, staff and faculty) undertook to connect and develop a mutuality of relationship across diverse stakeholders in Ecuador. We analyze this network building process from the perspective of cultural context, building trust 
Canadian Students Engaged in Ecuador Partnerships

and influence, and responding to social development needs of the host country. We present the perspective of the Ecuadorians as well as the Canadian students involved in this initiative.

\section{Literature Review}

\section{Benefits of Study Abroad in Areas of Global Competency}

The global competency benefits for students engaged in study abroad trips are significant. Universal competencies that appear to transcend both place and time include: a global mindset, personal qualities of high self-awareness, flexibility, adaptability, resilience, cross-cultural sensitivity and communication skills, ability to work in a multi-cultural context building cooperative relationships and partnerships, and an orientation to leading and managing change processes (Rowe, Etmanski and Heykoop, 2015). The Pyramid Model (Osland, 2018) provides a useful five-level structure to conceptualize these universal global leadership characteristics: 1) global knowledge; 2) threshold traits of integrity, humility, inquisitiveness and self-resilience; 3 ) attitudes and orientations (the global mindset) toward a global context; 4) interpersonal skills for working cross-culturally in teams; and 5) systems thinking skills. These competencies are evident among the students who have participated in short term study abroad trip, specifically in areas such as intercultural competency (Jackson, 2015; Cushner and Chang, 2015; Elola and Oskoz, 2008), emotional intelligence (Holtbrugge and Engelhard, 2016), moral and ethical reasoning (Luo and Jamieson-Drake, 2015), altruism and ability to appreciate cultural differences (Yang et al., 2016), perception of self and worldview in relation to culturally diverse others (Bell, Gibson, Tarrant, Perry III, and Stoner, L. (2016) and global citizenship awareness (Coers, Rodriguez, Roberts, Emerson, and Barrick, 2012). Pless, Maak, and Stahl (2011) summarized learning for business students in terms of responsible mind-set, ethical literacy, cultural intelligence, global mindset, self-development, and community building. Douglas and Jones-Rikkers (2017) concluded from their study on students who study abroad, students "increase their world mindedness as they move beyond their comfort zone and explore cultures and peoples who differ significantly from themselves and their personal experiences" (page 64).

In an investigation of student experiences in the Study Abroad for Global Engagement (SAGE) research project, Michael Paige and his colleagues (Paige et al., 2009) noted that study abroad is one of the most important experiences students can have due to the extent of engagement they have with people in their host country. In the SAGE project, global engagement is conceptualized, as civic commitments in domestic and international arenas, knowledge production (print, artistic, online, digital media), philanthropy (volunteer time and monetary donations), social entrepreneurship (involvement in organizations whose purpose and/or profits are to benefit the community), and the practice of voluntary simplicity in one's lifestyle (Paige et al., 2009: 31). The report concludes there is an increase in percentage of participants who become civically involved, produce new knowledge, practice new and environmentally aware lifestyles, make philanthropic commitments, and create or participate in social entrepreneurship. The SAGE study further found that students who went abroad were more likely to choose careers or further engage in study that was international in nature (ibid.).

However, there are gaps in the study abroad literature on what students learn in terms of the global relational competencies from building strategic partnerships with their international hosts. There is also a gap in the literature on the mutual benefits of these relationships. What aspects of global leadership do students learn and, more importantly, what aspect of strategic partnership building do students create through their engagements with their partners in an international setting? 


\section{Building International Strategic Partnerships}

We begin this section with a basic overview of how we define strategic partnerships. Typically, partnerships are defined in terms of pragmatic or instrumental purposes - existing primarily to achieve specific benefits or outcomes for the parties involved (Brinkerhoff and Brinkerhoff, 2011; Brinkerhoff, 2002). Businesses often espouse notions of instrumental purposes when they see partnerships as contracts or agreements to achieve specific economic gains. Contrary to this perspective is the normative view, often espoused by social or cultural communities, NGOs and civil society where partnerships are viewed as having intrinsic value as an end in themselves to support inclusiveness and equity. A third perspective combines features of pragmatic goals while anchored in normative values, to emphasize evolving networks and collaborative relationships that are equitable and accountable to all parties involved (see definition in above paragraph) to achieve benefits for all parties (Brinkerhoff, 2002).

Partnerships may be temporary or long lasting, depending on the goals of the parties, and/or the degree to which there is ongoing mutuality of commitment, trust and communication. They may be formal, defined through contractual or structured rules as in business or government contracts, and typically formed to share, or to provide people with, financial or technical resources to address specifically defined goals. Typically, formal partnerships prescribe who are the parties involved, the roles and duties, processes of engagement and the nature of interaction, services and activities to be performed. However formalized partnerships, so common to the business world, have little personal interaction. In contrast, other partnerships are informal associations or networks loosely arranged to address common interests. Many of these informal partnerships develop through personal contact and trust, resulting in the sharing of information and offering encouragement, advocacy or moral support. Informal partnerships typically evolve over time, as the personal relationships deepen and the parties discover common values and missions; strategic goals emerging for the respective partners as different needs emerge and objectives are identified (Rowe and Rivas, 2016). Change and adaptation is a common feature of informal dynamic partnerships.

Both formal and informal partnerships may have common or mutually interdependent benefits for all parties. However, formal partnerships, which have differing benefits for the respective parties, often vary significantly in size and resources, power and contribution. This means equality is seldom prescribed or even possible. It is not uncommon in formal partnerships for one party to have authority or power over the other, or where the sustainability of one party is dependent on the other (e.g. a military-humanitarian aid agency partner addressing a natural disaster). In contrast, strategic informal or network partnerships evolve and adapt with shared membership and equitable roles, rather than with rigid delineation or power imbalances (Rowe and Rivas, 2016). Decision making between parties may be separate or overlapping, based on various forms of consensus or consultation. Informal partners may have separate or shared goals (e.g. government-business partnerships vs. state and local enforcement departments).

It is useful to consider the potential benefits of informal strategic partnerships in terms of Brinkerhoff's (2002) framework of mutuality. According to Brinkerhoff (2002), partnerships should reflect:

“...mutual dependence, and entails respective rights and responsibilities of each actor to the others.... embedded in mutuality is a strong mutual commitment to partnership goals and objectives, and an assumption that these joint objectives are consistent and supportive of each partner organization's mission and objectives..."(page 22).

In mutuality of commitment, intangible benefits achieved by one party may have equitable value to the tangible and different benefits accrued to the other party. A sense of equity, rather than equality, as 
Canadian Students Engaged in Ecuador Partnerships

represented in commitment and responsibilities, is necessary for the partnership to form and thrive. According to Brinkerhoff's framework (2002) and considering the organizational strategic value of international development partnerships, the individuals involved derive both personal and professional benefits.

\section{Strategic partnership building requires leadership competency}

The leadership competencies for creating successful, authentic, sustainable, and dynamic partnerships include cultural awareness, capacity building and trust. Multi-party partnerships involving different cultural communities or organizations require sharing of knowledge and wisdom. However, developing an environment and structure where people feel comfortable enough to practice honesty, show vulnerability, take on challenging projects, and seek support when needed, requires high levels of trust (Gamble and Beer, 2017). Developing trust can be fostered through the use of facilitating factors: strong interpersonal skills, balancing power, defining roles and responsibilities, encouraging active participation, and shared decision-making (Nelson, Prilleltensky, and MacGillivary, 2001). Building capacity by developing trusting relationships that nurture people and their gifts may provide the opportunity for new perspectives, creativity, and allow the space for innovative ideas to surface. Inclusive holistic approaches to collaboration and partnerships can help "...develop [people] to be critical, confident and independent; aims to make learning a process of self-improvement that explicitly recognizes the self and the social context of learning and teaching, and recognizing the needs of the individual learner in the interaction" (Patel, 2003: 272). Collaboration in an international context requires creativity and communication to ensure stakeholders engage in discussions when designing their own processes aimed to serve mutual goals.

Visseren-Hamakers et al. (2007) argue relational trust building, while engaged in actual experiences of collaborative action, is more likely to succeed when it is based on a consensus of strategies and goals. Pattberg and Widerberg (2016) noted that most multi-stakeholder partnerships in the international arena fail to clearly identify or realize their intended goals. Critical conditions for success pertain to the relevance of actors involved, the relevance of process management, and the relevance of the problem-structure and broader situational context. Patterberg and Widerberg (ibid.) strongly advocate for networked governance among respective stakeholders, rather than formal contractual agreements, arguing for trust and transparency that creates equity in power: "Large power asymmetries in terms of sheer financial and human resources and information can be detrimental to trust among members from different sectors of society" (page 47).

Another key ingredient in supporting a successful dynamic partnership is engaging in intentional leadership for sustained change in complex environments. Leaders convene and bring people to the table, establishing the norms of communication and facilitating a pathway of action. Pattberg and Widerberg (2016) go on to discuss the role of leadership in effective dynamic partnerships to facilitate a process of goal setting, that is not based on rigid rules or formulas (as might be seen in formal contractual agreements), but based on consensual dialogue and collaboration. Using a framework of shared leadership offers a possibility for stakeholders with particular skills or knowledge to lead certain activities, leaving room for other stakeholders to take the lead elsewhere (Ife, 2013). When open and honest communication between stakeholders exists, the exchange of knowledge can allow people to discuss, learn, and plan various approaches to address issues.

Ernst and Chrobot-Mason (2011) describe the leadership role in forming sustainable dynamic global partnerships as a boundary spanning process, between different parties in leadership across respective organizational partners. It involves leaders within different organizations creating direction, alignment and commitment in service of a higher vision or goal. Six processes identified for forming partnerships include defining and clarifying roles of responsibilities of organizational partners, sharing of 
information and perspectives, connecting and linking people through social and professional engagement to build mutual trust and confidence, mobilizing action based on common purpose and shared intentions, weaving interdependencies and transforming respective identities through identification of emergent possibilities.

In the following section, we will identify the key pedagogical principles that underlie the activities of the MA in Global Leadership (MAGL) program at Royal Roads University. As such, while the study abroad literature primarily focuses on assessing the impacts on students, the emphasis that the MAGL program places on authentic and sustainable partnerships is foremost in the program's objective for equitable relationship building. In building mutually interdependent partnerships around a set of common goals, many interactions between the partners are social and informal in nature, allowing for the development of a trusting environment wherein stakeholders feel comfortable sharing their thoughts, opinions, or concerns (Lacey, Peel, and Weiler,, 2012). Wheatley (2006) stated, "if] power is the capacity generated by our relationships, then we need to be attending to the quality of those relationships" (page 40).

\section{Description of the MA in Global Leadership Program}

The pedagogical principles underlying the MAGL program have guided the design of the international trips to Ecuador. We intended that development of dynamic strategic partnerships in Ecuador would revolve around intercultural communication and cultural understanding which was embedded in the concept of global awareness together with concepts related to global leadership. These principles are reflected in a perspective of global leadership espoused by the program that embraces personal leadership, the leading of organizations, and enhancing community well-being (Rowe, Etmanski and Heykoop, 2016: 197). The three key competency domains stressed in the program include 1) personal leadership in a global context, 2) leading in a diverse global context, and 3) leading sustained change in complex environments. As such, the learning outcomes for students participating in the international trips pertain to understanding one's values, beliefs and behavior in the context of other people, being aware of one's orientation in the world, accountable for one's behavior and being open to learning. The program places emphasis on being resilient and adaptive in response to complex, challenging and stressful environments.

The MAGL international trip was created in part to develop new skills in leading in a diverse global context. The concept of global diversity is approached from an intersectional perspective, that includes ethnic heritage, language, religion, indigenous heritage, country of origin, and urban/rural community, as well as class, gender, sex, age, generation, disability, and more (Gopaldas, 2013). In contexts such as in the Global South, cultural differences create challenges for partnership engagement and can be compounded by attitudes of perceived superiority among members of the more economically advantaged group (Foller-Carroll and Charlebois, 2016). Culture contributes to one's identity, sense of belonging, and sense of community; acknowledging cultural orientation and attitudes is an integral element of international partnership building (Ife, 2013). In order for stakeholders from different cultural backgrounds to form equitable partnerships, there needs to be sensitivity to the differing cultural perspectives and needs of respective partners; which may evolve over time as the partnership develops (Pedersen, 2010; Heffernan and Poole, 2005, Bennett, 1993). Additionally, in the case of socio-political and economically disparate partnerships that involve a Global North organization (such as an academic institution or NGO) with a Global South organization, the economic and power inequities require special attention and collaborative action to ensure equalized participation (Martin and Griffiths, 2011; Powell et al., 2010). 
In order for the MAGL students to be successful leaders in a global context, they need to experientially acquire general understanding and specific knowledge of societal-level values and norms in countries different from their own. This experiential understanding moves beyond cultural stereotypes and mono-cultural models toward fluid, emergent, and dynamic intercultural and intersectional understandings of the diversity and ever-changing nature of human experience through direct experience. MAGL students are expected to enhance skills in intercultural interaction and communication. In the context of Ecuador, this was accomplished by having students engage in direct personal and professional conversations with multiple Ecuadorians across many sectors of the military, indigenous communities, NGOs, business, retail stores and tourism. Additionally during the trip, opportunity is created for students to facilitate learning sessions and projects in collaboration with their Ecuador partners.

Intercultural partnership and collaborations require attending to power equity. The MAGL students are frequently encouraged to be sensitive to behaviors of privilege that would create power imbalance in their interactions with Ecuadorians. Powell et al. (2010) recognized the inequities and power imbalances that were apparent between a group of American nursing research teams and partners in the Caribbean and Central/Latin America, and therefore defined a community engagement model to involve adaptive and recursive cycles of informing, consulting, collaborating and empowering. Powell noted the participatory partnerships created opportunity and a mechanism for input from local communities as well as generated knowledge that benefited the community.

\section{Building the Ecuador and MAGL Strategic Partnership}

Our case example and story begins in early 2015, when two senior military officers from Ecuador arrived at Royal Roads University, Victoria, Canada under the terms of a formal Memorandum of Agreement (MoU) with the University to complete a Master of Arts degree in a program of interdisciplinary studies. However, before long, and completely outside the curriculum outlined in the MoU, they connected with MAGL faculty and staff, deciding that the description of leadership studies was more closely aligned with their goals in coming to Royal Roads University. They enrolled in the MAGL intensive residency course which specifically targeted building a global mindset, developing intercultural communication, and enhancing personal leadership capacities of adaptability and systems thinking. These two military officers became closely bonded with a group of 10 Canadian students and four faculty and staff in the program, giving birth to a new international relationship that was extended to family members on all sides. This international relationship expanded to include two additional military officers and their families who arrived in Canada in early 2016 for their 18-month educational tenure. All four officers and families extended invitations to reciprocate hospitality in Ecuador.

Consequently, in June 2016, 2017 and again in 2018, a group of faculty, students and staff from Royal Roads University traveled to Ecuador to explore the county and to promote enhanced educational connections between Canada and Ecuador, as well as to weave new connections within and across different stakeholders and sectors within the country itself. The initial group of students called themselves 'global weavers' and henceforth this concept was introduced to subsequent cohorts of students. Over time, the Canadian team from the MAGL program weaved further connections between and across the Ecuadorian military and indigenous communities, military and civil society, and tourism leaders and indigenous social developers, developing common ground, purpose and action projects.

Underlying the explorations of the MAGL students, faculty and staff within Ecuador was the concept of dynamic strategic partnerships: building and evolving new relationships across different stakeholders to advance strategic benefit for respective parties. 
"Partnership is a dynamic relationship among diverse actors, based on mutually agreed objectives, pursued through a shared understanding of the most rational division of labor based on the respective comparative advantages of each partner. Partnership encompasses mutual influence, with a careful balance between synergy and respective autonomy, which incorporates mutual respect, equal participation in decision making, mutual accountability and transparency" (Brinkerhoff, 2002: 21).

As such, it was a dynamic strategic partnership that emerged as an outcome for the Canadian program and its partners in Ecuador. It was a form of partnership that was particularly suitable to the complexity of differences between a northern university group of students and a country in the Global South. Hence, the exact experience and the principles of global leadership and engagement were actualized as emergent, dynamic, and subject to the given context. The international context created conditions of complexity due to differences in the cultural, economic and political situations of the respective stakeholders (Burns and Worsley, 2015), and consequently the partnership continually evolved.

The story of Canadian students engaging with stakeholders in Ecuador is one of relationship building followed by the formation of a dynamic partnership to pursue interests of shared learning, opening of educational opportunities, and support for community development efforts that began with two indigenous communities. We tell this story as a case study describing how students in the MAGL program were involved in the development of the strategic partnership in Ecuador, using a process framework that embodies and practices key leadership competencies. This framework was formulated through multiple group discussions with students and staff involved in the study abroad trip over two years and content analysis of student reflection papers on their experience. The story, as told by the authors who themselves all participated in the Ecuador events, begins with individuals stepping forward to create a vision of what a partnership could look like, co-creating a shared knowledge of the respective cultural context, creating a trusting alliance between the Canadian and local Ecuadorian stakeholders, and identifying and bridging with stakeholders who are 'power influencers'. It illustrates how the stakeholder base expanded externally and internally in Canada and in Ecuador; focused on building and strengthening individual connections, then connecting different parties to support new networks, and, finally, reinforcing the partnerships through activities and strategic action.

\section{Leaders stepping forward to create a partnership vision.}

As previously noted, the story of the Canadian student-Ecuador partnership began with the two Ecuador military officers who arrived in Canada in 2015 to acquire a master's degree. With Ecuador poised for significant social and economic change, these military officers - both lieutenant colonels - had been tasked with enhancing their educational base so as to assume leadership roles in a modernization of the Ecuadorian army. In Ecuador, the military are seen to be key political and social leaders; subsequently, senior officers are sent all over the world to learn how to bring Ecuador into the $21^{\text {st }}$ century and to lead a transformation of the military. These two officers brought their families to Canada to support them in their own cultural adjustment to a different world, to learn English, and acquire new concepts of leadership. Within a few months, both officers made contact with the head of the MAGL Program, persuasively asked for special exceptions so as to enroll in courses mid term, began to develop friendships, and called on their new association with instructors and other students to provide them with assistance with both English language mastery and completion of course requirements. These officers saw an opportunity to learn leadership theory and practical skills that could help them in their mission to transform leadership within the military and in interaction with other sectors within their own country. The relationship, which initially was based on educational goals, deepened into a friendship when staff, faculty and students began to enjoy activities together at respective homes and in the community.

\section{Understanding the Ecuador cultural context.}


Understanding the Ecuador cultural context did not come from reading a book. It began with the interactions between the students and the Ecuadorian men and their families. While the Ecuadorian men were experiencing the culture of Canadian society, they shared many stories of people and customs in their own country. The Ecuadorians took advantage of classroom assignments to do presentations on the diverse geographical regions, the colonial and military history, and to discuss numerous indigenous, economic and political issues. As the Ecuadorians learned English, they assisted students, staff and faculty in their learning of Spanish. One faculty member began Spanish lessons with the wife of one of the men, while a University staff person began group lessons on campus. Books were given as gifts and websites explored as a way of acquiring knowledge of the respective cultures. The Ecuador men introduced their families to members of the University community, with shared meals, social conversation and play between children of the respective families. In Ecuadorian culture, true relationships are bonded when it involves the family. Ecuador is a country that is highly collective and focused on the family (Hofstede, 2018).

\section{Creating a trusting alliance between the Canadians and the Ecuadorians.}

Regular and ongoing social interaction and communication is important to the building of a trusting alliance between the respective partners. While initial contact was made through the classroom and mutuality of educational needs, the development of trust came through socializing activities and responding to real social and personal needs. In order to build trust, connections must be extended to the immediate family. The family culture in Ecuador is very inclusive of their children. Their children are not typically restricted to child-oriented activities as is typical for children in northern cultures, but instead they are included in events of their parents. It is not atypical to see children attend business type meetings with their parents. To build this inclusive relationship to the contact's family, it is important to refer to the names, school challenges, and milestones in the family's lives including acknowledgement of their holidays and reaching out and sharing information about ours. Relationship building is facilitated by the frequent use of internet communication using e-mail, texting and video conferencing apps. Texting is arguably the most common form of communication in the country although some of the older generation still prefer the phone. "What'sApp"1 can do text, as well as voice and video phone, thus it is the most commonly used means of communication. While there is a cost to download the What'sApp software in Ecuador, it is a reasonable cost and extremely efficient for international communication and while travelling in Ecuador. This communication software made it easy to maintain no cost text and telephone communication between individuals in Canada and individuals in Ecuador; like talking to a friend in the same city.

"WhatsApp" also has the capability of sharing photos; thus family photos are typically used for profile pictures and provide another means to reach out and engage in conversation. By building these partnerships through inclusive family relationships, we showed our openness for continuous dialogue, and used these opportunities to share knowledge of the university and purpose for the MAGL student trip to Ecuador. Consequently, as the Ecuadorian families in Canada were accepted into the families of staff, faculty and students in their host University, they in turn invited members of their Canadian hosts to spend time in their homes in Ecuador. Friendships and trust developed, as a precursor to the emergence of a goal and mission for an ongoing University to Ecuador country partnership.

\section{Developing a mutuality of mission.}

The military students from Ecuador suggested the Canadian students visit their country to learn about Ecuadorian ways as a way to enhance their development as global leaders. Meanwhile, the

${ }^{1}$ WhatsApp is a internet based software application (https://www.whatsapp.com/) 
Ecuadorians assured the Canadians that they were needed in-country to share their knowledge of leadership theory and practice so as to support new leadership development in the Ecuador military. The first international field trip was organized for students to travel to Ecuador the following summer of 2016. To make this happen, the MAGL Program Head and a program staff person took on the goal of getting University permissions through all levels of the University from school director, Dean and VP Academic, writing the international trip proposal, obtaining funding and arranging the travel logistics. Letters of invitation came from senior military leaders in Ecuador with a request for an ongoing educational partnership. The Canadian students were asked to engage students at Escuela Politécnica del Ejército (ESPE) in discussions on leadership and to deliver presentations on leadership and partnerships to military officers at the War College (a military academy for officers).

The discussion sessions and leadership presentations at ESPE and the War College served to cement the sincerity and authenticity of the partnership between the Canadian leadership students and the Ecuador military. The partnership was further strengthened when one student took on the mission of delivering a workshop on leadership for a Special Forces unit of the Ecuador army, in addition to providing ongoing consultations on developing stronger leadership practices through all levels of command. Another Canadian student established connections to undertake his capstone project in Ecuador, focusing on mentoring women in the Ecuador military. A mutuality of commitment, goals and benefit emerged between the two lieutenant colonels within the Ecuador military and Canadian coordinators of the MAGL program. Each party articulated the benefits of the learning opportunities for themselves, and acknowledged the value of the partnership as a whole for future endeavors. For example, this might be stated as 'I have learned so much about different leadership models which I am using in my job with my military officers. I hope you will speak to my officers when you visit our base so that they may share in this learning about different leadership methods.'

Two additional Ecuador military officers came to the Royal Roads campus the following year; thus, deepening and extending the relationship building process. The new Ecuadorian students sought out relationships with faculty, staff and Canadian students, initially for support and assistance in their classes and then for reciprocal learning. Friendships and socializing among Canadian and Ecuadorian families continued. The following year, another cohort of students traveled to Ecuador for a 12-day exploration of the country.

\section{Networking and bridging through in-country 'influencers'.}

The next step was for members of the MAGL program to bridge with influencers in Ecuador (i.e. individuals who are respected and in positions of influence in their sector or community) in order to expand and sustain emerging new partnerships. The four initial contacts within the Ecuador military (two lieutenant colonels and two majors) were asked to introduce the Canadian team to other members of the military in other locations. Connections were made with the Special Forces base, the Eloy Alfaro military cadet school and EIWIAS base (http://www.eiwia.mil.ec/), which includes Amazonian indigenous tribes who specialize in jungle missions. These introductions were often informal and emergent. For example, the MAGL group was introduced to a military officer on leave from northern Ecuador while shopping in a food market in Quito. Conversations followed and this individual volunteered to guide the student group in a northern indigenous area, serving as translator and informant on indigenous -military relationships. Other introductions of friends, family and work colleagues facilitated by our military contacts led to a talk with tourism students at the ESPE University, a dinner and conversation with Indigenous leaders working on water conservation issues in the Nagsiche region, and a visit and dialogue with leaders in a small town in the Amazon region working to implement a water and sewer treatment plant that will serve indigenous farmers as well as the town. These introductions have developed into friendships that have led to ongoing communication between some of the MAGL group members and, in some cases, also their respective families. Each new contact opened up discussions about educational opportunities in Canada as well as 
opportunities for new areas of learning in Ecuador; from these connections came additional linkages to other circles of "influencers". In the second year, we made contact with a private sector employee in the transport industry, and through various connections to two foundations leading cultural preservation in the North; these contacts also developed into friendships.

The story of the central Andes remote communities of Simiatug and Salinas is an example of how the MAGL program students and staff connected to different influencers in Ecuador, building bridges of assistance, communication and knowledge sharing. Towards the end of the first trip to Ecuador, members of the Canadian MAGL team connected with two education recruitment agents from Quito who had facilitated the referral of the Ecuadorian lieutenant colonels and majors to Royal Roads University. These two individuals took the Canadians to the Kichwan village of Simiatug to learn about a non-profit women's cooperative developed to combat extreme poverty in the community. There they met Cornelia who provided introductions to other members of the women's cooperative; Cornelia expressed a desire for an ongoing relationship with the Canadians saying the community needed help with expanding and marketing their craft and herbal products. The following year, the Canadians followed up with another visit to the community and while in the area connected to Pablo in the neighboring village of Salinas. Salinas was successfully operating several social enterprises only 70 kilometers from Simiatug but the two villages knew little about each other. Pablo was invited to visit Simiatug in order to be a translator for the Canadians. This contact led to an initiative by Pablo to promote eco-tourism with indigenous families in the Simiatug community. Pablo offered assistance to the folks from the Simiatug women's cooperative on how to develop a social enterprise market. Meanwhile, the Canadian students participated in a fund raiser to purchase a new commercial sewing machine for the Simiatug women's cooperative to increase their productivity. We planned a third student trip for the following year to enhance the development of a relationship between the two villages. Additionally a project is now underway by a research team from the Canadian University to support capacity development in social entrepreneurship.

As friendships deepened and expanded in Salinas and Simiatug, another Ecuadorian influencer facilitated a connection to the people of the Nagsiche River Basin. The MAGL students shared a meal with indigenous leaders from this area and discussed some of the significant and relevant challenges in their community. As a result, a new partnership is emerging with the indigenous leaders of the Nagische River around the issue of eucalyptus trees and their negative impact on water reserves ${ }^{2}$. This topic led to ongoing conversations between key members of the MAGL program on issues of community social cohesion, water and food security which will be a key issue for further discussion in upcoming international trips.

\section{Expanding the Ecuador learning opportunities.}

The bulk of the relationship building occurs when students are in-country with their Ecuador partners. However, during the year between the student trips, there is considerable conversation going on among the MAGL program staff and faculty and the existing 'influencers' in the country. These individuals in Ecuador introduced the Canadians to new 'influencers' (using e-mail, WhatsApp and skype). These contacts are explored as potential new learning sites and issues for further student trips. Since the student trip to Ecuador is currently an integral part of the second year MAGL curriculum, planning begins a year in advance on how to enhance existing partnerships and to develop new emerging partnerships; the travel itinerary is developed gradually to reflect these new relationships. All proposed trip activities are linked to the learning competencies and goals of the program.

\footnotetext{
${ }^{2}$ With cash crops of eucalyptus trees being grown in the area to aid Ecuador's growing lumber export industry, and the current inability of local authorities to deal with significant wild patches, the water supply of local farmers and communities is being destroyed (Magdaleno, 2017). Local leaders have created a model to bring back the water source, but the model is too expensive to be replicated in a substantive way (Padilla, personal conversation, 2017).
} 


\section{Expanding the Canadian student weaver base.}

Deliberate efforts are taken to enhance the MAGL student weaver base each year. All students who have participated in an Ecuador experience are encouraged to stay connected to individuals they met during the trip and to find ways to give back to the country or to the MAGL program. Information on past Ecuador trips and existing partnerships is posted on a student website that is accessible by former students of the trip as well as new students who will be involved in the future trips. One student created a video on highlights of the Ecuador trip that was widely distributed to all former and new students. The women's cooperative in Simiatug started an online campaign, with help from the MAGL program, in order to purchase a new commercial sewing machine. Past and current students in the program made donations. Another former student made a follow-up trip to the country and shared pictures and information with other students on the community website. Two former students have continued to support leadership development work with the Ecuador military. ESPE University invited two students back to make presentations at their International Congress. Former students, who self-identified themselves as 'weavers' use a variety of communication tools to keep connected to members of their own cohort and have reached forward into existing cohorts to tell the story of the Ecuador partnerships and encourage them to become engaged with the country as global leaders. Former students have come into the classroom of the current students to describe their experiences in Ecuador and to share their leadership projects.

Learning about the Ecuador partnerships begins early in the MAGL program; new students are given information on Ecuador history and geo-political and socio-economic issues. Considerable information is provided to new student groups on how to navigate the cultural norms and what to expect during the upcoming student trip. Additional information is provided over the year as part of the process of preparing students to be actively engaged from the moment they arrive in the country. Students are encouraged to think about their future leadership role in the country. This is so they can see themselves as part of a growing contingent of MAGL students who are connected to various initiatives going on in the country (e.g. military leadership development, social and economic development in Salinas or indigenous environmental sustainability in the Amazon). The numbers of 'student weavers' has increased from the original 7 the first year, 4 in the second year, and then 7 in the third year; for a total of 18 students.

Where there is interest, we seek to facilitate introductions between students and key individuals in Ecuador in advance of the international trip. As mentioned, each year the staff and faculty of the MAGL program build a travel itinerary on the contacts and activities of the previous year, with each group of incoming students required to give presentations at the two host institutions in Ecuador (ESPE and the War College) and to meet representations from the military and the two indigenous communities. After the formal presentations at each of these institutions, mingling occurs between the Canadian students and officers from the War College or students at ESPE University. Pictures are taken and What'sApp numbers exchanged. The networking relationships continue to build. The Ecuadorians tend to be assertive in establishing new relationships with each incoming group of students. Some of these relationships become ongoing.

\section{Strengthening individual connections through personal relationship.}

Personal stories, having meals together, and sharing of family and pet pictures has proved to be an important part of building personal relationships. Lifestyles are compared. Where possible, visits are made to each other's homes. Socializing between members of the MAGL program and their friends in Ecuador continue in-between the formal trips that happen only once a year. When the MAGL program group arrives in Ecuador each year, gifts are exchanged. Genuine offers are made to reciprocate with homestays should children of the Ecuadorian friends travel to Canada for schooling. 
Canadian Students Engaged in Ecuador Partnerships

\section{Maintaining and adjusting the purpose and mission of the partnership.}

An underlying purpose for all interactions between the MAGL students and faculty with their Ecuador partners and friends was the promotion of educational opportunity for Ecuadorians and development of global leadership capabilities for both the Ecuadorians and Canadians. This theme resonated in the conversations and presentations - whether individuals were engaged in formal presentation in front of a group of military officers, or during a discussion on the goals of the new Ecuadorian President Lenín Moreno over a lunch in the old district of Quito, or a chat with a parent about international university options for their 17 year-old son. At all times, the Ecuadorians and MAGL students pursued a goal of understanding each other's world and what were their needs as an individual, for their children, and for their country. The goals of the partnership evolved from an original focus on knowledge sharing of respective cultures to building of intercultural communication competencies and, by the third year, to developing skills to support specific social development initiatives in Ecuador (e.g. the social enterprise in the village of Simiatug). Ecuadorians stated an important goal for them was to strengthen their English-speaking skills and likewise the MAGL students, staff and faculty sought to develop basic communication skills in Spanish reading and speaking. Students reported that learning basic Spanish helped them to connect with the Ecuadorians, to feel less helpless doing ordinary tasks (e.g. shopping in a store) and to better understand the cultural context. Commonalities and differences were identified in the lives of the Canadian vs. Ecuadorians as well as between different groups of Ecuadorian cultures. Another goal for students and the Ecuadorians that evolved over time was to better understand the dynamics of power and inequities within the Ecuadorian country, but also within other countries in South and North America and around the world. Understanding the election of President Trump in the United States was a frequent topic of conversation. As the relationships deepened, so were there deeper and more meaningful discussions addressing those issues that both parities felt were significant in their respective countries. Change begins with new knowledge and changes in mindset and mental paradigm. This was happening and evolving over time amongst all parties within the Canadian team and the Ecuadorian partners.

\section{The Perceived Experience of the Ecuadorian Partners}

The Ecuadorian partners included the four military officers who participated as students in the MAGL program as well as many other individuals in country who liaised with the Royal Roads University group (including international education staff and faculty from ESPE University, the Ecuador War College, military officers in various units around the country, community social entrepreneurs working in various villages and towns, government energy officials, and indigenous leaders). From the view of the Ecuadorian authors in this paper, many benefits accrued to them as a result of their association with the MAGL program. They describe having developed greater cultural awareness on the differences between Canadian and Global South cultures; how values of individualistic and collectivism impact on different ways of living and the development of relationships. For example, one author noted,

Ecuadorian society is a collectivist society where group goals take priority over individual ones. Individuals pay primary attention to the needs of their group and will sacrifice personal opportunities, [for the group] while Canadian culture is defined as an individualist society.

In spite of these differences between the cultures, one Ecuadorian former MAGL student reported "the cultural awareness which developed through my educational experience at Royal Roads University helped me to be inserted into the Canadian culture and also to better understand different cultures back in Ecuador" (personal communication)". 
The Ecuadorians students reported developing better communication skills as a result of working with the Canadian student 'global weavers'. Communication is a basic skill to understanding cultures and societies. As noted:

During the academic process and their trip across Ecuador, we achieved a goal of overcoming the barrier of language, and gained capacity in understanding each other, exchanging ideas and promoting solutions for problems in the Ecuadorian community. (personal communication, Ecuadorian MAGL student).

One of the learning goals of MAGL is intercultural interaction and communication which refers to "increase capability to interact with people from different cultures through developing decision making process exercises and using intercultural approaches" (W. Rowe, personal communication, February 1, 2016). The capability to interact with people was demonstrated during the process of developing alliances and friendship between families and friends.

Ongoing partnerships were another benefit for the Ecuadorians. During the trips to Ecuador, the MAGL students gave presentations and engaged in multiple discussions about leadership theories and experiences. Discussions with many military officers and non-officers, cadets, and civilian students, often focused on sharing different perspectives on world and Ecuadorian events. According to one of the Ecuadorian students, "we learned how small changes can generate big changes around the world because everything is connected and some actions in their system could affect other systems differently" (personal communication, Ecuadorian former student). As follow up to these discussions, one of the Ecuador students invited two fellow Canadian Armed Forces members to an Ecuadorian military unit located in the jungle to speak about the importance of military woman in security forces and to encourage their goals for advancement in the military.

Finally, the Ecuadorian students noted how important it was to engage with non-military stakeholders in order to achieve success in their in-country mission and goals. They reported that their experiences in the classrooms of Royal Roads University and with the MAGL students, faculty and staff during their travel in Ecuador had strengthened friendships and also led to the development of strong relationships across different stakeholders in Ecuador who had similar interests as global leaders.

"We perceive the teachers, alumni, staff and friends as stakeholders who can contribute to the development of project ideas, strategies or conferences in various Ecuador communities" (personal communication, Ecuadorian former student). According to Boon, Bawole and Ahenkan (2013) "stakeholder participation is one of the cardinal principles of good project management" (page 38). "The relationship that the Ecuadorians built with the Canadian students was based on trust and friendship and taught us how to work with key stakeholders in order to achieve social goals" (personal communication, Ecuadorian former student).

Following are the words of Lt Colonel Fabricio Varela, one of the first military officers who attended the MAGL program and acted as a key liaison contact and 'influencer' for the MAGL students during their travels in Ecuador:

I was able to change my thinking about my personal capacities for work in complex global systems. I learn [ed from the] global leadership team group also how [to] respect different perspectives and approach[es] over issues. The professors gave me trust for saying my point of view on complex topics, and my classmates help[ed] me to develop communications skills of listening, thinking and speaking. According to social construction theory, people can build their understanding of the world, in coordination with other people (Leeds-Hurwitz, 2009). In my case I learn [ed] different perspectives and [about] other systems of the education, [I have] two 
identities; Canadian and Ecuadorian. These are the frameworks for cultural identity for me and my family. I was a student at RRU. My life changed when I arrived in Victoria, the best place in the world. I have traveled to different countries but never knew one like Canada which is quiet, clean, safe, and people are very polite. My values of humility, honesty and loyalty are of good use there also. I like that culture; I like the system of education. I am not the same Fabricio now. Thanks to the program leadership for helping this Ecuadorian soldier, student and now Professor in the war college to develop my skills on leadership and help me in understanding theories [of] leadership. As an officer in the army, I learned in this program how I must train and prepare my troops better with critical thinking in all levels and how they must face the new threats in different scenarios. Now I have [new] background [on] how I can see the world because overwhelming complexity in today's environment makes the need for systems thinking ever even more necessary. Systems thinking enables people to see interrelationships rather than linear cause and effect chains; to see processes of change. Most important is working in teams because "great teams do not hold back with one another. They are unafraid to air their dirty laundry. They admit their mistakes, their weaknesses, and their concerns without fear of reprisal" (Lencioni, 2005: 44). However, I can conceptualize teams as interdependent groups who share common purpose and goals and must work collaboratively in order to achieve those goals.

Lt Colonel Robert Vargas made similar comments about how he was changed by his experiences in the MAGL program and by working with the Canadian students, faculty and staff who had come to Ecuador. He reflects on how his encounters with the Canadian culture forced him to change his military perspectives on privilege within his own country:

My studies in Canada and specifically in Royal Roads University, motivated me to leave [my normal] sphere, from a clearly established world, with rules and limits, paradigms and beliefs, to a new world filled with challenges, where the rules and limits can change, and are more difficult to understand; where my paradigms and beliefs had to disappear to face the new world (without mistakes). For example, in my world in Ecuador, I am an active duty military officer with a rank of officer, for which I receive a salary; I occupy positions of university administrative professor; and my dominant language is Spanish; I have my own house and car. In my world in Canada I went from being a soldier to being a civilian, which forced me to adapt to a society of different perspectives, from war to peace. I stopped being a teacher and I became a student, which forced me to change my conception of guidance to be guided to knowledge or with my dominant language of Spanish I had difficulties in expressing all the thoughts that my brain kept producing to English.

In order to adapt to my new world, I had ....to put my humility to the test, to shut up many times, [be] honest and accept my deficiencies. This experience, applied in the context of learning was very positive, because I managed to strip and confront my rules, beliefs, limits and knowledge, which allowed the learning of new concepts, a fresh analysis of people and their realities. I managed to renew myself, to learn new concepts and relearn previous concepts.

Therefore, I experimented with new relationships of friendship, outside the university and within it. My circles of friends were civilians, mainly migrants in Canadian lands, who were quick to help us in our adaptation to the new world. My new friends allowed me to understand and know new paradigms of life; many of them had the courage to launch themselves to conquer their dreams without looking back, without shelter or support that is there for when they slip, with the indestructible bravery of that person who conquers the unimaginable. 
Lt Col. Vagas also speaks to what he brought back to Ecuador after his tenure as a student in Canada, which was reinforced by his continued association with the MAGL program and the Canadian team:

When I returned to Ecuador, I necessarily suffered a re-adaptation conflict...... It is increasingly easy to understand the differences in concepts between the different micro societies that exist in my country. I have developed the ability to capture the differences between the different human groups that make up the great Ecuadorian society, and to better understand their differences, which often manifest themselves in violent internal conflicts. In my Ecuador there are many immigrants who have left their homeland and even their family to seek the dreams of a better destination; therefore my respect for them and their courage has increased considerably.

Currently, as a battalion commander in the Ecuadorian Army in the Ecuadorian jungle, I have learned a lot from our natives. They look at nature, fauna and flora, as their living habitat, which if lost, will be very difficult for them to survive. ... [Additionally] I have overcome my fear of making mistakes when learning another language, which has given me great openness to learn the language of the natives of this land. As a result the personal relations between the soldiers and the [native] community have improved, and my relations of friendship with the people of the sector are magnificent and varied, from the local government authorities, elders and heads of the aboriginal communities, to the children.

[I am] motivated to collaborate with my university, RRU [Royal Roads University] and my teachers, in developing a knowledge exchange program. I feel that they can learn a lot by living reality in Ecuador. They need to confront [their] reality, with the reality experienced by other societies, with different needs and different objectives, [which] will allow [them] to develop a learning and relearning process, which will improve not only [their] theoretical knowledge, but [help them] to accept the reality of the diverse world, scattered and different.

Finally, the exchange with students of the Universidad de ESPE, civil and military, has allowed the two communities, Canadian and Ecuadorian, to share knowledge, ideas and [wisdoms], which will be reflected in a better global society.

\section{The Perceived Experiences of Canadian MAGL Students}

At the time of this writing, 18 Canadian students from Royal Roads University had participated in the international trips to Ecuador. Most of them had studied alongside the Ecuadorian students in one or more classes prior to their trip to Ecuador, and then interacted with them again once they were inside the country of Ecuador. Here are some examples of what the MAGL program students describe:

- a transformational experience

- new ways of seeing their place in the world

- being mindful of their own values and perspectives while listening to others

- understanding the privilege of the north and western societies versus living in the global south

- how necessary it is be adaptive and flexible when interacting with people from a different society or culture

- communicating through shared experience and emotional intelligence as a way to overcome language barriers

- using inquiry and an open learning orientation to understand differences 
- recognizing that strategic partnership is fundamentally derived first from developing personal relationships and then a sharing of knowledge and perspectives before one can focus on accomplishing tasks and strategic objectives

The Canadian students describe interacting with a very wide range of stakeholders within an already diverse country, including indigenous leaders, business owners, and community members; military commanders and their subordinates; language instructors and teachers; university students; community leaders and council members; tour operators, drivers, and guides, among others. Student received 'welcomes' from every person they met, which did wonders in developing trust and new relationships. One of this paper's contributors noted, "the Ecuadorians, both civilian and military, welcomed me with open arms and although we had to work through a language barrier, it only seemed to bring us closer together" (student reflection paper 2017). Being new and being immersed in a strange culture, the students were excited, attentive but dependent on the acceptance of their hosts, thus simultaneously anxious and hesitant. This experience helped the students to identify with what is the experience of newcomers and immigrants to their own country.

Learning to communicate in the context of a language barrier enhanced learning opportunities of the students. It required focusing on cross-cultural communication and using content that would be culturally bridging (e.g. eating together), interpersonal skills and using emotional or cultural intelligence to understand each other, making people feel valued by understanding the audience, empowering others by using connective teaching techniques, and team building skills. Students exercised other global leadership competencies such as flexibility and adaptability to cope with differences in how time and schedules were perceived and to adapt to the day and activities as they emerged. The concepts of time and schedule were more relaxed in Ecuador compared to Canada; by not being aware of this factor one could easily react negatively if self-awareness was not exercised. The students saw themselves as learners during all phases of their trip which helped them to open their minds, be accepting and adaptable, which contributed to understanding the cultural differences and similarities.

Students talked about the importance of systems thinking, as a way of perceiving the multiplicity of 'intersectionality' of demographic factors as they affect privilege and oppression of people (Golpadas, 2013). Frequent conversations occurred on these concepts through the lens of race, class and gender as experienced in Ecuador, and in contrast to social identity structures in Canada. Systems thinking is also a way of unlearning individual biases: "Systems thinking is a gateway to seeing interconnections. Once we see a new reality, we cannot go back and ignore it. More importantly, there was awareness of 'seeing' has an emotional connection" (Laszlo 2012 para 3).

"I discovered while on this journey that often my assumptions, biases and place of privilege negatively influence the lens I use to see the world around me... This journey to Ecuador showed me that despite believing I was aware of my thoughts and actions I still need to confront my assumptions, biases, judgments and privilege because in the end these create boundaries blocking my ability to be a leader who can create sustained change in complex environments, or lead and work in diverse global contexts" (student personal reflection, 2017). Self-awareness requires deep reflection of personal biases, but it also requires inquiry into how others perceive issues. As one contributor to this paper noted:

Self-awareness and recognizing personal biases was also an important component of the trip. It was important to be constantly aware of communities we were in and the people we were in communication with and be in a constant state of inquiry and not impose a 'Canadian' or 'North American' way of thought during the trip. A key example of this was when we spoke to the first nation's community members near Tena who had to reclaim their land because the government allowed oil exploration on the land they lived on. It was important to ask them what they viewed as help and what their vision for the future of their community looked like, rather than make 
assumptions about what they would want the future to look like. One of the group members inquired if they were interested in having English taught at their school rather than assume that they want English in their schools. This communication was respectful and inquisitive which made the dialogue extremely educational (student reflection paper, 2017).

Another of this paper's contributors wrote:

I'd never really been exposed to the Global South and hadn't really left the comfort of living in the developed world. I quickly realized that I have been living in my own little bubble and sheltered from a lot of things. I was often hearing about different traditions around the world but not necessarily engaging with them. This was my first time being immersed in a culture, first hand. Long bus rides allowed a lot of time for reflection and helped us develop a greater bond as a cohort [the Canadian students from a particular intake year]. There was a sense of intercultural interaction and communication everywhere we went! From military bases, to supermarkets, restaurants and hotels, I found it quite endearing that we worked together to translate and make sense of what was happening. ...I remember holding back tears the entire time, and I wasn't sure why. Perhaps it was seeing 3 families living in such a small place and seemingly content with their conditions was a very humbling experience. I think I felt empathetic towards them at first, but also reminded myself that maybe they do not define happiness in the same way most of us do from a western perspective. Our usual definition of happiness and success is measured by obtaining consumer goods or living in a big house or driving an expensive car. It is wrong of me to assume that they are unhappy or that I am supposed to feel bad for them. Perhaps time spent with family and more time outdoors is more meaningful to them. Ever since that encounter, I have started reflecting more on needs and wants.... During the trip, I believe we were all careful not to impose western values or act as if we are coming to "save" the people of Ecuador or act like we know what is better for their communities. I think this is a challenge that all leaders in the global world face... In conclusion, my time spent in Ecuador was truly the experience of a lifetime and exposed me to situations I will never and would never be able to experience had I travelled there on my own. There were elements of leadership in all situations, whether formal or informal (reflection paper, 2017).

For another contributor in this paper, what was impactful about his time in Ecuador was learning about the sense of community in some of the small villages and towns that he visited. "I feel that it was the sense of community in Salinas not only was it a community by our standards it seemed as if the entire town was a family. I truly believe that Nigerian proverb "it takes a whole village to raise a child" was demonstrated in Salinas. I have never experienced that before anywhere in all my travels. Salinas and Simiatug will forever have a special place in my life, because one is the example of what could be, and the other is the perfect example of things that will be when a community comes together" (reflection paper, 2017).

Students were conscious at all times that the international trip was intended to be about personal leadership development as well as developing strategic partnerships. This experience is wonderfully expressed by one of the paper contributors,

I was introduced to Commando Fabricio Cordova, a former MAGL student, and it was clear that he valued his experiences at RRU by his warm welcome and his engagement in conversation. I began to understand that the partnership between RRU, the War College, and ESPE University had both political and enhanced visibility benefits. The cross-cultural exchange between active military members, students at ESPE University, and our cohort allowed for discussions surrounding various leadership styles, values, and strategies. Although the Ecuadorian military and RRU are structured organizations, I believe the impetus of this partnership was organic and 
built on relationships and trust. Members of the Ecuadorian military who experienced the intensity and transformational aspects of the MAGL program had the opportunity to share and develop ideas, such as this international exchange. However, I also understand that in order for this international cultural exploration trip to occur, formalized memos of understanding (MOUs) were necessary for clarity and to demonstrate mutual respect. Having a broad overview of the partnerships that had formed in order to allow our cohort to participate in this cultural exchange further emphasized the importance of strategic partnerships. On Wednesday, June $28^{\text {th, }}$ 2017, I gave my first international presentation to members of the Ecuadorian military at the War College in Quito, Ecuador. Admittedly, I was extremely nervous at the thought of presenting my small Nepal research project to various ranking members of the military. Olson, (2018) stated, "global emotional intelligence involves both self-management and cultural acumen" (page 60), personal competencies that were certainly enhanced as a result of my presentation. First, I learned that I need to further develop ways to become comfortable in front of a crowd. I believe the content was strong however, I often found myself pausing in nervousness and turning back to look at my presentation on the large screen. I think spending more time going over my presentation and becoming familiar with the environment that I am presenting in could help me prepare in the future. Secondly, and perhaps more importantly, I experienced how the cultural differences enhanced my learning as I gained a great appreciation for the dialogue that formed around my presentation. For example, working with a translator to communicate and to create a welcoming environment where participants felt comfortable to work through communication barriers. Personally, I was unsure of how my work with remote villages in Nepal would resonate with members of the military. However, I was pleased when a military officer, who was impressed by my work, asked how I was able to get teachers to set up their own infrastructure. The officer told a story about how he had tried to work with local Indigenous populations to get work done but had been unsuccessful. I explained that it wasn't about me "getting" people to do things" it was about me facilitating conversations, exchanging ideas, and allowing time for my partners to take ownership. In contrast, I had another military officer express his concern that what I was doing was not leadership. I was not offended by his comment; I was intrigued to learn from his perspective. Although brief, we had a good conversation about the relationship between ownership and sustainability. I shared that, in my experience, I could not force people to take action. However, I could discuss the pros and cons of initiatives and allow time for people to take action. I understand how the officer may not think my approach was practical considering the large system he operates in. The military has varying objectives, time frames, and methods that, from a systems thinking perspective, may be challenging to alter. Overall, exploring strategic partnerships in a global context while strengthening my own personal leadership has, without a doubt, increased my understanding and my confidence.

Reflecting on the international cultural leadership exploration experience, I have recognized the power of outrospection: self-growth through building relationships and empathetic thinking with others. I built my confidence during my first international presentation, I learned about social enterprises from the prospective of two countries, and I was inspired by the story of an Indigenous community making a difference. The connecting theme throughout the journey was the importance of strategic partnerships. Personally, as a co-founder of a not-for-profit organization who is considering partnering to expand, I realize it is critical for our organization to build our partnerships. Connecting with individuals and organizations that have benefited from partnering has provided an intrinsic source of motivation as I begin to strategically plan the next steps for our organization. I also became aware of the value of formal and informal interactions; formal adds structure and direction, whereas the informal helps build relationships and teams. In my experience, it is easy for organizations to become caught up in formal, structured, and overly bureaucratic systems. Failing to utilize the power of informal interactions results in a missed opportunity to improve communication, build relationships, and trust amongst teams or 
stakeholders. As I continue to develop my skills as a global leader, I am becoming increasingly aware of the benefits of shared experiences, shared leadership, and experiential learning. In many ways, this international field trip lifted text from our MAGL course material off the page and connected theories and ideas to people, and to leaders. Globally conscious citizenship requires empathy, understanding, and the desire to work together, strategically, for positive change. It is through cultural exchanges, discussions, idea sharing, and partnership building that innovation has the chance to flourish.

Particularly illustrative are the experiences of Chief Petty Officer Sean Wilcox who was a Canadian student in the MAGL program but also a member of Canadian military. He had tremendous credibility in Ecuador and connected well with several individuals around the topic of mentoring. His interests and connections in Ecuador led him to develop a mentoring program for women in the Ecuador military, as part of his master's degree capstone project.

The connections I made in Ecuador ranged from military leaders to academic professionals who share the same ambitions and perspectives as myself.

To name just a few was my host Lt Col Fabricio Varela, who was the driving force and benefactor of my project in Ecuador. He is the lead instructor at the Senior Military Leadership Academy for Command officers. Fabricio and I worked together to develop and implement new concepts to the Ecuadorian army, such as the concept of mentorship and how the spectrum of leadership can be applied to the military ideology of leadership. Another key person who was and will probably be the biggest influence on the Ecuadorian mindset is [the Director of international students at ESPE University] in Quito. [We] worked together on the concept of how men could best mentor women in the professional context. Female mentorship is a new concept within the professional workforce in Ecuador as women are just now being introduced into middle management. [The Director] and I have identified that Ecuador does not have a National Action Plan for the implementation or integration of women in Ecuador; [consequently] we will be working together to draft a National Action Plan [that] she will then [move] forward through her connections within the Ministry of Higher Education in Ecuador.

The words of Sean Wilcox are insightful and significant. Most, if not all, the students learned they are not the purveyors of knowledge and solvers of a developing country's challenges.

The biggest thing I learned in Ecuador was that we are not the people with the answers. It was my first experience working internationally outside the military. I learned that I may have a concept or idea, but it may not fit the societal needs of another country; all the basic ideologies work well together but working internationally it is a must to remain flexible at all times. I learned that the Ecuadorian people will band together to move new concepts forward, they as a population who put much more emphasis on the collective well being than the individualist approach of most North Americans; their concept of family does make it very easy to push a new concept forward [but only] if the people agree with it.

\section{Summary and Discussion}

While the Royal Roads University international partnership with the military and other organizations in Ecuador yielded tremendous benefits for the individual students involved (both Canadian and Ecuadorian), the value of this relationship goes far beyond the individuals involved and instead is reflected in the deepening of a mutually valued relationship between a northern University and a South American country. Royal Roads University has established trusted contacts in Ecuador that it continues to maintain and reinforce with respect to a variety of international education matters, including 
development and marketing of appropriate curriculum for the student in the Global South. In Ecuador, various representatives from the military, NGOs and indigenous communities seek out information and support from key contacts at Royal Roads University (including staff with the MA in Global Leadership Program) for new knowledge and education that supports their various leadership and social development needs. The lessons learned in the process of establishing these trusted contacts include the importance of focusing on the smallest of acts to create trust. We established trust far ahead of time through continuous conversation and continually engaging in small reciprocal acts of generosity.

In this continually expanding network of contacts, Ecuadorians enthusiastically welcomed their Canadian visitors. Contacts were extended in an emergent way for whatever purpose the Canadians needed. In Canada, the MAGL students, faculty and staff and many members of the broader University community reciprocate through hospitality and assistance. Key to this ongoing informal but strategic partnership is the four Ecuadorian military men and the MAGL program coordinator, Lisa Corak. These individuals comprise a core ambassador group that continually seeks to strengthen their personal relationship with each other, take the initiative to establish new contacts and create new opportunities of learning for both the students of the MAGL program, and the Ecuadorians. The network of relationships is continually evolving to meet different and mutually beneficial needs. The lessons learned here include the importance of expanding networks through the contacts made, while deepening the established links. Deepened relationships created trust between us and others.

There is a strategic partnership between Royal Roads University, the Ecuador military and ESPE focused on enhancing educational opportunities within both countries. However, it is important to emphasize that this is sustained not by the Memorandum of Agreement (MOU) that was written many years ago but by the development of personal and professional relationships created when students travel to Ecuador as part of their studies on global leadership. Individual students come and go, have transformational experiences and earn their master's degree. Some maintain contact with individuals from Ecuador, while others go on with their lives. A core nucleus remains active, connecting the University and key individuals in Ecuador. The primary lesson learned in this emergent process is the recognition of organic relationship building. MOUs mean very little without personal involvement in the engagement process.

The partnership between Royal Roads University, the Ecuador military and ESPE continues to grow and adapt as an informal social and organizational network. As new contacts are made, new relationships and smaller partnerships have emerged to reinforce and sustain the broader network. For example, two individuals proceeded to work on a research paper together. In another instance, a former student, Chief Petty Officer Sean Wilcox is working with key leaders at ESPE University to develop a mentoring program for professional women. This concept of networked partnerships for strategic advantage is not new. In the business community, networked collaborations involve two or more organizations that have "combined the best skills or core competencies and resources of their organizations to co-create a value proposition more compelling and relevant to the consumers' needs and expectations" (Romero and Molina, 2011: 447). Less common are references to collaborative networks in the NGO or educational sector, perhaps because the value proposition is so much harder to define as a stated common objective. The key lesson learned is that strategic partnership relationships should be free to be emergent and not stagnant or rigidly confined; they need to shift, expand and adapt to the changing and evolving needs of the parties. As relationships change, it is important to continually give back in ways that have emerged as relevant to the time and place. Trust and personal friendship in maintaining collaborative international networks is also critically important (Lister, 2000).

In this area of University partnerships with multi-stakeholder entities in a Global South country, more needs to be learned about how students can successfully bridge the cultural divides, weave networks 
of relationships that support the international partnerships, and co-create a value proposition important to all parties.

\section{References}

Appel, G. (1990).Costing social change. In M.Dove (Ed.),. The Real and Imagined Role of Culture in Development: Case Studies from Indonesian. Honolulu, HI: Honolulu and Hawaii University Press.

Bell, H.L., Gibson, H.J., Tarrant, M.A., Perry III. L.G., \& Stoner, L. (2016) Transformational learning through study abroad: US students' reflections on learning about sustainability in the South Pacific, Leisure Studies, 35(4), 389-405.

Bennett, M. J. (1993). Toward ethnorelativism: A developmental model of intercultural sensitivity. In R. M. Paige (Ed.), Education for the Intercultural Experience. Yarmouth, ME: Intercultural Press, 21-71.

Bouwen, R., Craps, M., \& Santos, E. (1999). Multi-party collaboration: Building generative knowledge and developing relationships among unequal partners in local community projects in Ecuador. Concepts and Transformation, 4(2), 133-151.

Boon, E., Bawole, J. N., \& Ahenkan, A. (2013). Stakeholder participation in community development projects: An analysis of the quadripartite model of the International Centre for Enterprise and Sustainable Development (ICED) in Ghana. Community Development, 44(1), 38-54.

Brinkerhoff, J. M. (2002). Government-nonprofit partnership: A defining framework. Public Administration and Development, 22(1), 19-30.

Brinkerhoff, D.W., \&. Brinkerhoff, J.M. (2011). "Public-private partnerships: perspectives on purposes, publicness, and good governance. Public Administration and Development, 31(1), 2-14.

Burns D., \& Worsley S. (2015). Navigating Complexity in International Development: Facilitating Sustainable Change at Scale. Practical Action: Rugby

Collyns, D. (2018). Ecuador referendum could buck South America trend by banning re-election. The Guardian, retrieved from https://www.theguardian.com/world/2018/feb/02/rafael-correa-ecuadorreferendum-ban-re-election

Coers, N., Rodriguez, M.T., Roberts, T.G., Emerson, H.C., \& Barrick, R.K. (2012). Examining the student impacts of three international capstone experiences. North American Colleges and Teachers of Agriculture Journal, 56(2), 55-62

Cushner, K., \& Chang, S. (2015) Developing intercultural competence through overseas student teaching: checking our assumptions. Intercultural Education. 26(3), 165-178.

Douglas, C. \& Jones-Rikkers, C.G. (2001). Study abroad programs and American student Worldmindedness. Journal of Teaching in International Business, 13(1), 55-66.

Elola, I. \& Oskoz, A. (2008). Blogging: Fostering intercultural competence development in foreign language and study abroad contexts. Foreign Language Annals, 41(3), 454-477. 
Ernst, C., \& Chrobot-Mason, D. (2011). Boundary Spanning Leadership: Six Practices for Solving Problems, Driving Innovation, and Transforming Organizations. NY: McGraw Hill Professional.

Foller-Carroll, A., \& Charlebois, S. (2016). The attitudes of students and young professionals toward volunTourism: A study abroad perspective. International Journal of Culture, Tourism and Hospitality Research, 10(2), 138-160.

Gamble, E., \& Beer, H. (2017). Spiritually informed not-for-profit performance measurement. Journal of Business Ethics, 141(3), 451-468.

Green, M. F. (2007). Internationalization of community colleges: Barriers and strategies. New Directions for Community Colleges, 138, 15-24.

Green, B. F., Johansson, I., Rosser, M., Tengnah, C., \& Segrott, J. (2008). A multiple case study of nursing student s' international experiences. Nurse Education Today, 28 , 981-992. doi:10.1016/j.nedt.2008.06.003

Gopaldas, A. (2013). Intersectionality 101. Journal of Public Policy \& Marketing, 32, 90-94.

Heffernan, T., \& Poole, D. (2005). In search of "the vibe": Creating effective international education partnerships. Higher Education, 50, 223-245. https://doi.org/10.1007/s10734-004-6352-2

Hofsted, G. (2018) Country comparison. retrieved from https://geert-hofstede.com/ecuador.html .

Holtbrügge, D., \& F. Engelhard, F. (2017). Study abroad programs: Individual motivations, cultural intelligence, and the mediating role of cultural boundary spanning. Academy of Management Learning \& Education, 15(3), 433-455.

Ife, J., (2013). Community Development in Uncertain World; Vision, Analysis and Practice, Paper 2. Cambridge University Press, New York.

Jackson, J. (2015). Becoming interculturally competent: Theory to practice in international education, International Journal of Intercultural Relations, 48, 91-107.

Kingsbury, D., McKay, J.H., Hunt, J., McGillivray, M., \& Clarke, M. (2016). International development: Issues and Challenges, 3rd ed., Palgrave, London.

Lacey, G., Peel, V., \& Weiler, B. (2012). Disseminating the voice of the other: A case study of philanthropic tourism. Annals of Tourism Research, 39(2), 1199-1220.

Leeds-Hurwitz, W. (2009). Social Construction of Reality. In S. Littlejohn, \& K. Foss (Eds.), Encyclopedia of Communication Theory Thousand Oaks, CA: Sage Publications, 892-895.

Lencioni, P. (2005) Overcoming the Five Dysfunctions of a Team. San Francisco, CA: Jossey Bass.

Lazlo, K. (2012). From Systems thinking to system being. http://www.magentawisdom.net/systemsthinking--being/from-systems-thinking-to-systems-being, An excerpt from Beyond systems thinking and the role of beauty and love in the transformation of our world. Presentation at the 55th Meeting of the International Society for the Systems Sciences at the University of Hull, U.K., on July 21, 2011. 
Lister S. (2000). Power in partnership? An analysis of an NGO's relationships with its partners. Journal of International Development, 12(2), 227-239.

Lincoln Commission, (2005). Abraham Lincoln Study Abroad Fellowship Program, retrieved from http://www.nafsa.org/uploadedFiles/NAFSA_Home/Resource_Library_Assets/CCB/lincoln_com mission_report(1).pdf?n=6097

Luo, J. \& Jamieson-Drake, D. (2015). Predictors of Study Abroad Intent, Participation, and College Outcomes. Research in Higher Education, 56(1), 29-56.

Magdaleno, J. (2017, August 28). Indigenous farmers fight eucalyptus damage to water source in Ecuador. Mongabay Series: Global Forests. Retrieved from: https://news.mongabay.com/2017/08/indigenous-farmers-fight-eucalyptus-damage-to-watersource-in-ecuador/

Martin, F., \& Griffiths, H. (2011). Power and representation: A postcolonial reading of global partnerships and teacher development through North-South study visits. British Educational Research Journal, 38(6), 907-927.

Osland, J.S. (2018). An overview of the global leadership literature. In M.E. Mendenhall, J. S. Osland, A. Bird, G. R. Oddou, M.J., Stevens, M. L., Maznevski, \& G., \& K. Stahl, G. (Eds) Global Leadership: Research, Practice, and Development, ( $3^{\text {nd }}$ ed.). London: Routledge, 57-117.

Nelson, G., Prilleltensky, I., \& MacGillivary, H. (2001). Building value-based partnerships: Toward solidarity with oppressed groups. American Journal of Community Psychology, 29(5), 649-677.

Pachaysana Institute (2018). Rehearsing Change: Empowering Locally, Educating Globally, retrieved June 29, 2018 from https://www.pachaysana.org/rehearsing-change)

Paige, R.M., Fry, G., Stallman, E.M., Josić , J., \& Jon, J. (2009). Intercultural Education, 20:sup1, S29S44, Study abroad for global engagement: The long-term impact of mobility experiences. Intercultural Education, 20, 29-44.

Patel, N. (2003). A holistic approach to learning and teaching interaction: Factors in the development of critical learners. The International Journal of Educational Management, 17(6), 272-284.

Pattberg, P., \& Widerberg, O. (2016). Transnational multistakeholder partnerships for sustainable development: Conditions for success. Ambio, 45(1), 42-51.

Pedersen, P. (2010). Assessing intercultural effectiveness outcomes in a year-long study abroad program. International Journal of Intercultural Relations, 34(1), 70-80.

Pless, N., Maak, T. \& Stahl, G. K. (2011). Developing responsible global leaders through international service learning programs: The Ulysses experience. Academy of Management Learning and Education, 10, 237-260.

Powell, D., Gilliss, C., Hewitt, H., \& Flint, E.P. (2010). Application of a partnership model for transformative and sustainable international development. Flint Public Health Nursing, 27(1), 54-70. 
Romero, D., \& Molina, A. (2011) Collaborative networked organisations and customer communities: value co-creation and co-innovation in the networking era. Production Planning \& Control, 22(5-6), 447-472.

Rowe, W., Etmanski, C., \& Heykook, C. (2015). A masters degree in global leadership: A Story of development. In F. W. Ngunjiri. and S. Madeson (eds), Developing women as global leaders. Charlotte, NC: Information Age Publishing, Inc. (

Rowe, W., \& Rivas, E. (2015). NGO partnerships and boundary spanning in the Dominican Republic: Leadership strategies and competencies. Presentation at the $17^{\text {th }}$ Annual International Leadership Association Global Conference. Barcelona, Spain, October 17, 2015

Rubalcaba Bermejo, B., Slavova, S., Kim, M.D., Merino De Lucas, F., Franco-Temple, E., Victor, J.M., \& Ferrer Morera, G. (2017). Innovation for Productivity Growth in Ecuador: Uunlocking Constraints Through Horizontal and Cluster Development Policies (Vol. 3. Washington, D.C.: World Bank Group. Retrieved from http://documents.worldbank.org/curated/en/829651501612235402/Innovation-for-productivitygrowth-in-Ecuador-unlocking-constraints-through-horizontal-and-cluster-development-policies

Stebleton, M. J., Soria, K. M., \& Cherney, B. (2013). Going global: College students' international experiences and self-perceived intercultural competencies. Frontiers: The Interdisciplinary Journal of Study Abroad, 22, 1-24.

Velz, H.P, MacLeod, M.J., \& Knapp, G.W. (2018). Ecuador. Encyclopedia Britannia, retrieved https://www.britannica.com/place/Ecuador

Visseren-Hamakers, I.J., Arts, B., \& Glasbergen. P. (2007). Partnership as Governance Mechanism In Development Cooperation: Intersectoral North-South Partnerships for Marine Biodiversity. Cheltenham: Edward Elgar Publishing.

Wheatley, M. (2006). Leadership And The New Science: Discovering Order in a Chaotic World (3rd ed. ed.). San Francisco: Berrett-Koehler.

World Bank Group (2017). Economy Profile of Ecuador. Doing Business 2018. World Bank, Washington, DC. (O World Bank. https://openknowledge.worldbank.org/handle/10986/28633 License: CC BY 3.0 IGO."

Yang, M., Luk, L., Webster, B., Chau, A., \& Ma, C. (2016). The role of international service-learning in facilitating undergraduate students' self-exploration. Journal of Studies in International Education, 20(5), 416-436. 